\title{
Editorial
}

\section{Health humanities}

\author{
P Ravi Shankar \\ Editor, JMCJMS
}

Medical humanities ( $\mathrm{MH}$ ) developed in the 1970s as a counterpoint to the dominance of the sciences in medical and health professions education. The subject/discipline aimed to provide a contrasting perspective of the arts to western, scientific medicine. Recently some authorities have suggested replacing the word 'Medical humanities' with 'Health humanities' [1]. The authors suggest the term 'health humanities' more accurately reflects the interdisciplinarity of the discipline and also highlights the distinction between and importance of health in distinction to medicine. Health humanities may also be more reflective of the fact that the subject is no longer confined to medical schools but is an important part of the curriculum in many other health professional schools.

In 2007 I was lucky to have been able to initiate a voluntary medical humanities $(\mathrm{MH})$ module for interested students at the Manipal College of Medical Sciences, Pokhara [2]. I was fortunate to have the assistance of a small but committed and motivated group of faculty members and the sessions were interesting and fun. We were also successful in facilitating a workshop on Medical humanities $(\mathrm{MH})$ at the College of Medical Sciences in Bharatpur. The workshop was attended by pharmacists, nurses, pharmacy students and nursing students in addition to medical students and faculty. Sessions were conducted for both faculty members and students at KIST Medical College, Lalitpur, Nepal $[3,4]$. The faculty sessions were also attended by nurses, paramedical personnel and pharmacists.

Theater of the Oppressed (TO) was developed by the noted Brazilian theater personality, Augusto Boal as a means of combating external political and socioeconomic oppression. Rather than being mere 'spectators' members of the audience become 'spect-actors' and try to develop solutions for the problem/S facing them on stage. Later TO was used to deal with internal oppressors and also to provide participants with a first-hand perspective of the situation of the oppressed. In India, the Centre for Community Dialogue and Change (CCDC) has conducted a number of workshops on TO for educational institutions. They also conduct frequent trainers' workshops. At KIST Medical College in Lalitpur, a three-day TO workshop was conducted for interested students and faculty [5]. TO could serve as an important and fun means of exploring the health humanities. 
In a small land area, Nepal has a rich diversity of languages and cultures. Many students from countries like India and Sri Lanka also study in Nepal. A variety of languages are spoken and the country has a rich artistic and cultural heritage. At the Patan Academy of Health Sciences (PAHS), a medical school with the mandate of creating doctors for rural Nepal, Dr Courneya and her team have been using 'Heartfelt images' as a means of getting medical students to explore art and the humanities. She has been conducting an art competition under the theme, 'Mero muthu, mero kala' (My heart, my art) for many years. In an article published previously I had briefly mentioned on the need to develop $\mathrm{MH}$ and the health humanities in Nepal [6].

Health humanities in Nepal should take advantage of the immense cultural and linguistic diversity found within the country. I feel the discipline should be driven forward by the enthusiasm and creative energy of interested faculty members in various institutions. Like I had written before a rigid, centrally imposed curriculum can be counterproductive. The module should be fun and should use small group, active learning strategies. At Aruba we have been using reflective writing assignments as a means to help students explore various aspects of $\mathrm{MH}$ [7]. Reflective writing assignments, art work, art competitions and retreats can play an important role in the health humanities. The humanities can serve the important role of providing a voice to the disadvantaged and the underprivileged. Patient voices and stories do not find much expression in South Asia and MH can serve as a medium to bring these to the forefront.

The various uses of $\mathrm{MH}$ in medical education have been well described in the literature [8]. I am confident that with the right 'push' health humanities can take root and develop in Nepal, not only in medical but also in nursing, pharmacy and other health professional schools.

\section{REFERENCES}

1. Jones T, Blackie M, Garden R, Wear D. The almost right word: The move from medical to health humanities. Academic Medicine published online December 20, 2016.

2. Shankar PR. A voluntary Medical Humanities module at the Manipal College of Medical Sciences, Pokhara, Nepal. Family Med 2008;40:468-70.

3. Shankar PR, Piryani RM, Singh KK, Dhakal A, Shakya A. Knowledge, attitude and perceived skill levels at the beginning and conclusion of a medical humanities module. Australasian Med J 2013;6:392-6.

4. Shankar PR, Piryani RM, Karki BMS. A medical humanities module for faculty members at KIST Medical College, Imadol, Lalitpur. J Clinical and Diag Res 2011 (Suppl-2); 5:148992.

5. Shankar PR. A three day workshop on the theatre of the oppressed in a Nepalese medical school.Australasian Med J 2012:5:440-2.

6. Shankar PR. A need to develop medical humanities in Nepal. Kathmandu University Med J 2008; 21:146-7.

7. Shankar PR, Rose C, Toor A. Student feedback about the medical humanities module in a Caribbean medical school. Education in Med J 2016;8:41-53.

8. Macnaughton J. The humanities in medical education: context, outcomes and structures. BMJ Med Humanities 2000;26:2330 doi:10.1136/mh.26.1.23

\section{Correspondence to:}

Prof. P Ravi Shankar

Xavier University School of Medicine \#23, Santa Helenastraat, Oranjestad Aruba, Kingdom of the Netherlands. E-mail: ravi.dr.shankar@gmail.com 